\title{
SCANDINAVIAN JOURNAL OF MATERIALS SCIENCE
}

This is the first editorial for the new journal Scandinavian Journal of Materials Science. This editorial intends to give a background and insight into the motivation behind the formation of a Scandinavian journal in material science. The idea for the journal came from a random online search for journals connected to vital research areas in Scandinavia, specifically materials science. Materials science in Scandinavia is internationally very strong, of course historically originated from raw materials and via several important findings (e.g. the discovery of new elements, spectroscopy techniques) and also connected to significant research infrastructures (e.g. MAX IV and ESS). In addition, Scandinavia has a significant industrial sector and innovation climate within the field. Thus covering the value chain from education, research to industrialization. The investigation was also fueled by all the advertising emails from open access journals calling for papers, and the difficulty to verify the journal credential or quality. The result was astounding; there are zero (or very few) active materials science journals originating in Scandinavia. The established high-impact material science journals are all connected to the major publishing companies. Thus, the idea to form a Scandinavian journal was born. The next step was to try to find a publisher and via a further search, Medical Journals Sweden was found. The publisher is based in Uppsala.

The journal's scope is to encompass all parts of material science, publishing papers, reviews, communications, and conference proceedings - all with open access, a rapid review process and low publication fees. The strategy is to establish the journal as a high-quality option to publish materials science research findings. The journal strives towards building on the ongoing robust material science research in Scandinavia. The editorial board is international but with a majority of the board members spread over materials science strongholds in Scandinavia. It is also the intention of the editors to include historical perspectives on the development of materials science research and significant industrial achievements in unique papers. The development of new research areas and products by entrepreneurial-minded persons or companies within the existing structures has led to the establishment of the cross-disciplinary field of materials science.

Håkan Engqvist

Editor-in-Chief Scandinavian Journal of Materials Science

Håvard Haugen

Co-Editor Scandinavian Journal of Materials Science 